\title{
Memory psychophysics for pyridine smell scale
}

\author{
NAOYUKI OSAKA \\ Otemon-Gakuin University, Ibaraki, Osaka, Japan
}

\begin{abstract}
Power law exponents for perceived and remembered pyridine smell were obtained. The result indicated that the size of the memory exponent obtained was about 37\% larger than that of the perceived exponent for a pyridine smell. The data can be explained in terms of overestimation and underestimation at the higher and lower ends of the stimulus range employed during memoryretrieval processes. The stimulus, an unpleasant pyridine odor, has highly emotionally involved memory-coding properties and appears to be over- and underestimated at the upper and lower extremes of the stimulus range, respectively, during memory processing.
\end{abstract}

Several recent investigations have indicated the similarity of perceived and remembered (i.e., memory-retrieved) magnitude in visual perception (e.g., Kerst \& Howard, 1978). In several studies using visually coded mental representation, subjects were asked to make internal psychophysical judgments based on memory representations when they were asked to remember and compare the assumed sizes of two concrete objects from memory (Moyer, 1973; Osaka, 1983). It seems that this wellestablished method for investigating psychophysical judgment can also be applied to the analysis of memoryretrieved representation for olfactory stimulus.

In the present study, the assumptions are that (1) the memory code activated by the memory tag-clue has much in common with the perceived experience of the pyridine and (2) a subject can estimate the retrieved pyridine smell by using a ratio scaling. A psychophysical power law relating memory processing to perceptual processing was tested here using a method of magnitude estimation.

\section{METHOD}

\section{Stimulus}

Six white squeeze bottles (each $25 \mathrm{ml}$ ) were fitted with flip-top spouts and were used for delivery of air-diluted pyridine $\left(\mathrm{C}_{3} \mathrm{H}_{5} \mathrm{~N}\right.$ ) (Amoore \& Ollman, 1983; Jones, 1955, 1958a, 1958b; Olfacto-Labs, 1983). The density of the pyridine was well above threshold and was changed from 1.23 to 3.43 in steps of $0.4 \log$ units. The duration of each stimulus presentation was approximately $1 \mathrm{sec}$, and the order of presentation was randomized for each stimulus. One of six different color chips (i.e., violet, green, red, black, yellow, and blue) was stuck on each bottle as the memory clue.

\section{Subjects}

Eight college students with normal olfactory sensitivity, as tested by Sherman, Amoore, and Weigel's (1979) pyridine sensitivity scale, served as subjects.

Part of the paper was presented at the 23rd ICP congress at Acapulco, 1984. This work was supported in part by Grant No. 59510073 from Ministry of Education, Japan. The author's mailing address is: Department of Psychology, Otemon-Gakuin University, Ibaraki, Osaka 567, Japan.

\section{Procedure}

The subjects made magnitude estimations of each air-diluted pyridine stimulus that was provided by the experimenter (Amoore, 1970; Guadani, Buttery, \& Okano, 1963). The subjects were asked to rate the perceived magnitude of each pyridine stimulus $1.5 \mathrm{sec}$ after the offset of the stimulus presentation by assigning the appropriate number from Sherman et al.'s (1979) scale and trying to commit the stimulus to memory (Osaka, 1983). Each stimulus was rated twice by each subject and the perceived pyridine exponent was calculated from averaged estimates. The subjects were trained to retrieve each stimulus from memory according to the color labels (i.e., a paired-associate training for olfactory stimulus with color). Intertrial intervals were $1 \mathrm{~min}$ long in order to eliminate smell adaptation. The temperature of the experimental booth was kept at $23^{\circ} \mathrm{C}$ during the experimental session. Subjects made estimates of these perceived stimuli from memory 10 days after the learning session. The order of memory retrieval was randomized. As in the procedure employed in the percept condition, each stimulus was rated twice by each subject, and the memory exponent was calculated from the averaged estimates.

\section{RESULTS AND DISCUSSION}

The straight line in a log-log plot fitted to the data using the least squares procedure indicates that goodness of fit

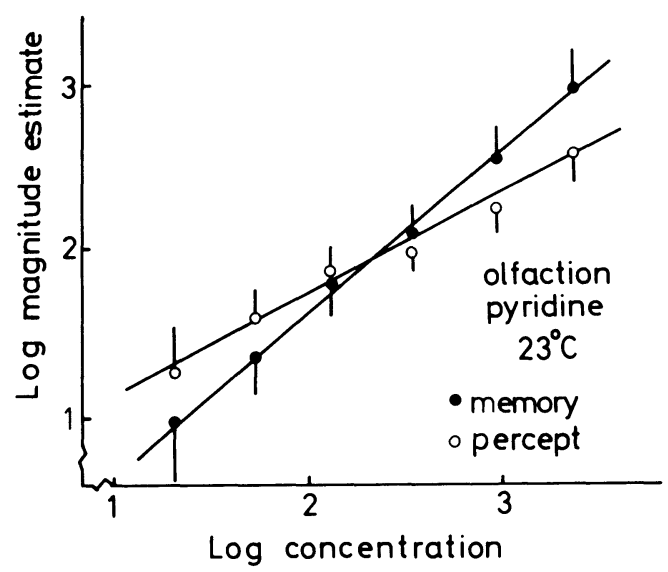

Figure 1. Log perceived/remembered estimate as a function of $\log$ pyridine concentration for percept and memory conditions. Vertical bar indicates 1-SD unit. 
was fine for both percept and memory conditions $\left(r^{2}=0.97\right.$ and 0.93 , respectively). As Figure 1 shows, the results suggest that the memory exponent $\left(\beta_{m}=0.52\right)$ was significantly larger $(p<.05)$ than the perceptual exponent $\left(\beta_{p}=0.38\right)$. The magnitude of $\beta_{m}$ is approximately $37 \%$ larger than that of $\beta_{p}$. This increase of memory exponent suggests that retrieved psychological sensation magnitude is likely to be over- and underestimated at the upper and lower extremes of the stimulus range, respectively (Osaka, 1984a); however, the estimates for the stimuli in the middle range remained almost the same for both memory and percept conditions. Since an unpleasant smell like pyridine appears to be coded in the memory in a highly emotionally driven manner, pyridine smell is likely to be over- and underestimated at either end of the stimulus range during memory retrieval.

\section{REFERENCES}

AMOORE, J. E. (1970). Molecular basis of color. New York: Thomas. Amoore, J. E., \& Ollman, B. G. (1983). Practical test kits for quantitatively evaluating the sense of smell. Rhinology, 21, 49-54.
Guadani, D. G., Buttery, R. G., \& Okano, S. (1963). Odor thresholds of some organic compounds associated with food flavors. Journal of Science of Food \& Agriculture, 14, 761-765.

JONES, F. N. (1955). The reliability of olfactory thresholds obtained by sniffing. American Journal of Psychology, 68, 289-290.

JoNEs, F. N. (1958a). Scales of subjective intensity for odors of diverse chemical nature. American Journal of Psychology, 71, 305-310.

JoNES, F. N. (1958b). Subjective scales of intensity for three odors. American Journal of Psychology, 71, 423-425.

Kerst, S. M., \& HowARD, J. H., JR., (1978). Memory psychophysics for visual area and length. Memory \& Cognition, 6, 327-335.

MOYeR, R. S. (1973). Comparing objects in memory: Evidence suggesting an internal psychophysics. Perception \& Psychophysics, 13, 180-184.

OLFACTO-LABS. (1983). Is the sense of smell affected? User's manual.

OsAKA, N. (1983a). Memory psychophysics for perceived length and area. Bulletin of the Faculty of Letters, Otemon-Gakuin University, 17, 15-28. (In Japanese)

OsAKA, N. (1984a, September). Psychophysical modality matching functions for perceived and memory processes. Paper presented at the 23rd ICP Congress, Acapulco.

OsaKa, N. (1984b). Psychophysical scaling of mental image for visual, olfactory, taste, and tactile processes. Bulletin of the Faculty of Letters, Otemon-Gakuin University, 18, 1-15. (In Japanese)

Sherman, A. H., Amoore, J. E., \& Weigel, V. (1979). The pyridine scale for clinical measurement of olfactory threshold: A quantitative re-evaluation. Otolaryngologie \& Head Neck Surgery, 87, 717-733. 